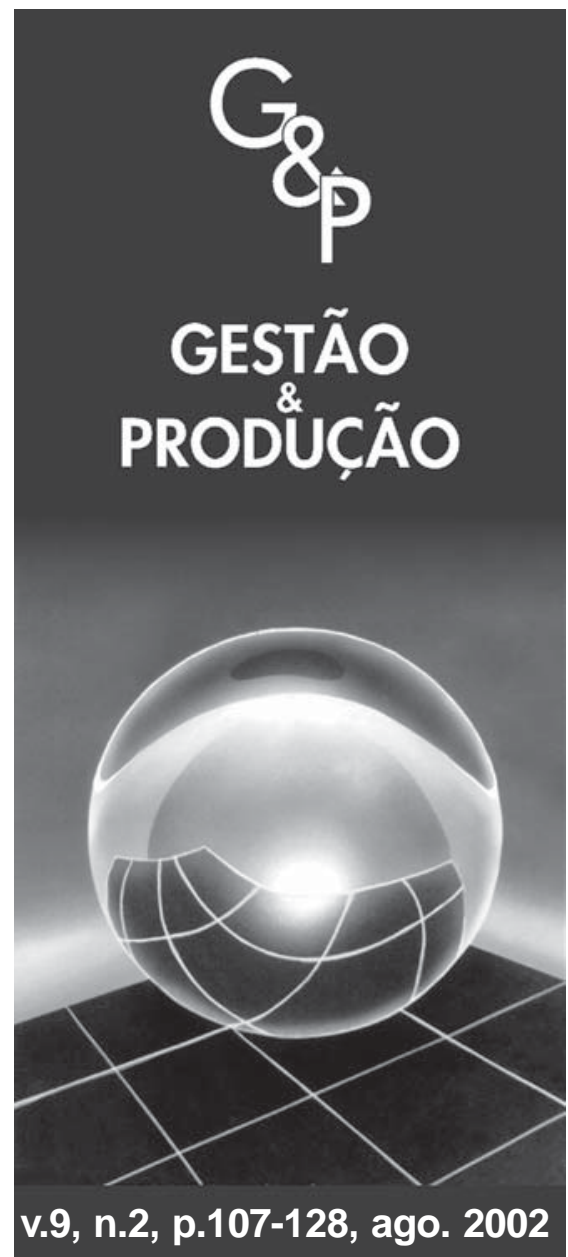

\title{
ANÁLISE DO SISTEMA LOGÍSTICO DE RECEPÇÃO DE CANA-DE-AÇÚCAR: UM ESTUDO DE CASO UTILIZANDO SIMULAÇÃO DISCRETA
}

\author{
Ana Paula lannoni \\ Reinaldo Morabito \\ Departamento de Engenharia de Produção, \\ Universidade Federal de São Carlos, \\ C.P. 676, CEP 13565-905, São Carlos, SP, \\ e-mails: papi@iris.ufscar.br, \\ morabito@power.ufscar.br
}

\section{Resumo}

Os sistemas logísticos são hoje fundamentais para melhorar a eficiência operacional de usinas de cana-de-açúcar, pois atuam na integração de operações agrícolas e industriais. O presente artigo apresenta um estudo do sistema de recepção de cana em uma das maiores usinas do Brasil, a Usina São Martinho, localizada na região de Ribeirão Preto, SP. O trabalho foi desenvolvido com o objetivo de analisar o desempenho desse sistema, compreendido da balança até as moendas, e investigar configurações e políticas alternativas para sua operação. Em razão das diversas fontes de incerteza e da complexidade operacional do sistema, o método utilizado teve por base técnicas de simulação discreta. As principais medidas de desempenho avaliadas são relacionadas ao tempo médio em que os veículos permanecem no sistema de recepção e à quantidade média de cana descarregada nas moendas por unidade de tempo.

Palavras-chave: açúcar, sistema de recepção de cana, simulação, logística, agroindústria.

\section{Introdução}

Drincipalmente nas últimas décadas, o setor agroindustrial canavieiro iniciou um processo de pesquisa e desenvolvimento que garan- te seu destaque no setor agrícola brasileiro. As usinas de cana-de-açúcar procuram se adequar ao cenário da economia nacional por meio de inovações como a melhor forma de integrar as áreas agrícola e industrial. Segundo Yamada 
(1999), a necessidade da implantação de alternativas de técnicas, equipamentos e recursos que beneficiem o planejamento e o controle do processo produtivo ocorre em razão do aumento de competitividade no setor. Várias inovações importantes foram relatadas em Eid (1996), destacando-se as relacionadas ao aprimoramento dos sistemas logísticos por meio de novas estratégias gerenciais para o transporte da cana. Os sistemas logísticos são fundamentais para melhorar a eficiência operacional das usinas de cana-de-açúcar. Um problema importante nesses sistemas é como coordenar os processos de corte, carregamento e transporte de cana do campo até a área industrial, de maneira a suprir adequadamente a demanda necessária na área industrial. Segundo Caixeta et al. (1998), o custo do corte, do carregamento e do transporte representa $30 \%$ do custo de produção da cana, e somente o transporte equivale a $12 \%$ desse total.

Idealmente, o sistema de recepção, que compreende operações como pesagem, amostragem, armazenagem intermediária e descarga de cana nas moendas, deve operar com um fluxo de cana transportada do campo à usina que permita alimentação uniforme das moendas. Se tal situação não ocorre, pode haver paradas nas moendas, o que é altamente prejudicial à usina. No entanto, manter a moenda funcionando com quantidade de cana descarregada insuficiente para alimentá-la pode implicar desperdícios de energia e aumento de custos. O fluxo ideal de cana transportada do campo para a usina pode sofrer com algumas variações do ambiente, como clima (em dias chuvosos, o transporte sofre as consequiências das dificuldades da colheita), localização das frentes de corte (quando a colheita precisa ser feita em áreas muito distantes da usina) etc. Por outro lado, a ociosidade de caminhões no pátio também é motivo de grande preocupação, pelo alto custo de investimentos, mão-de-obra e combustível, além da falta que esses caminhões fazem no campo, pois se não houver caminhões vazios disponíveis para receber a cana colhida na frente de colheita, gera-se ociosidade, envolvendo máquinas e operários. Outro fator relevante é que a cana, quando picada ou inteira (principalmente se for queimada), pode se deteriorar caso permaneça por muito tempo em estoque ou em fila no pátio de descarga.

O presente artigo tem por objeto de estudo o sistema de recepção de cana em uma das maiores usinas do Brasil, a Usina São Martinho, localizada na região de Ribeirão Preto, SP, com capacidade de moagem de cerca de 36 mil toneladas de cana por dia. O estudo foi realizado com o objetivo de analisar o desempenho do sistema de recepção de cana, compreendido da balança até as moendas, e investigar configurações e políticas alternativas para operação desse sistema. Em razão das diversas fontes de incerteza e da complexidade operacional do sistema, o método utilizado teve por base técnicas de simulação discreta, utilizando o sofware Arena. As principais medidas de desempenho avaliadas foram relacionadas ao tempo médio de espera dos caminhões no sistema de recepção, à quantidade média de cana descarregada, de acordo com a capacidade de moagem da usina, e à taxa de utilização das moendas. São poucos os trabalhos similares na literatura com foco no sistema de recepção de cana. Alguns trabalhos que utilizaram simulação para analisar sistemas do setor sucroalcooleiro podem ser encontrados em Yoshizaki (1989), Mathew \& Rajendran (1993), Hahn (1994), Lopes (1995) e Yamada (1999). É reconhecida a importância desse setor no interior do Estado de São Paulo, particularmente nas regiões de Araraquara, Ribeirão Preto e São Carlos, onde diversas usinas estão localizadas.

O trabalho está organizado da seguinte forma: a Seção 2 apresenta brevemente o sistema de recepção de cana do estudo de caso, a Seção 3 descreve resumidamente o modelo de simulação utilizado e sua validação, a Seção 4 analisa os resultados obtidos para a configuração original do sistema, a Seção 5 aplica o modelo para analisar configurações alternativas para o sistema e a Seção 6 apresenta as conclusões e as perspectivas para pesquisas futuras. 
Convém salientar que o modelo de simulação do presente trabalho é um refinamento do modelo de Iannoni (2000), uma vez que restrições anteriormente não consideradas, por exemplo, a limitação de capacidade das moendas e a dependência entre pontos de descarga de uma mesma moenda, foram incorporadas neste modelo.

\section{Sistema de recepção de cana}

A Usina São Martinho tem tido efetiva participação nos processos evolutivos do setor sucroalcooleiro, com investimentos próprios em pesquisas e em meios de modernização, alcançando, assim, altas taxas de produtividade que a colocam entre as maiores do mundo (Waack et al., 1998). Em particular, o setor de transporte de cana tem representado papel de destaque no processo de modernização e de investimentos em pesquisas dessa usina. Os principais problemas estão relacionados à economia de combustíveis, à racionalização da frota e à manutenção do fluxo de cana para alimentar as moendas. Uma das metas a serem atingidas no sistema de transporte é reduzir a ociosidade e o tempo de ciclo dos caminhões. O tempo de ciclo é compreendido desde a entrada do caminhão na usina, seu descarregamento e sua volta ao campo, seu carregamento no campo, até seu retorno à usina, novamente. Em outras palavras, busca-se a otimização das operações que envolvem esses veículos, cuja ociosidade, nas áreas agrícola e industrial, resulta em altos custos para a usina.

A Figura 1 apresenta resumidamente o sistema de recepção de cana na Usina São Martinho (trajetória da balança até as moendas). Ao chegarem na usina, os veículos passam pela balança, onde são coletadas, entre outras informações, o peso e o número do caminhão. Antes de seguirem para o setor de despacho, alguns veículos devem ser sorteados para realizarem amostragem no laboratório de sacarose. Após receberem ordem de despacho nesse setor, os veículos seguem para o ponto de descarga e esperam para descarregar nas esteiras das moendas (descarga) de acordo com a especificidade de cada caminhão e a capacidade da moenda. A ordem de prioridade dos veículos em cada fila está indicada na Figura 1. A usina possui três moendas: as moendas A e B moem cana inteira e picada, possuem, respectivamente, dois e três pontos de descarga $\left(A_{1}, A_{2}, B_{5}, B_{6}\right.$ e $\left.B_{7}\right)$ e capacidade de moagem de $450 \mathrm{t} / \mathrm{h}$. A moenda $\mathrm{C}$ moe apenas cana picada, possui três pontos de descarga $\left(\mathrm{C}_{10}, \mathrm{C}_{11}\right.$ e $\left.\mathrm{C}_{12}\right)$ e capacidade de moagem de $600 \mathrm{t} / \mathrm{h}$. Após a descarga de cana nas esteiras das moendas, os veículos retornam ao campo para carregar e reiniciar o ciclo. Se o motorista julgar necessário, o caminhão deve passar antes pelos serviços de manutenção e borracharia, evitando a incidência de problemas mecânicos durante o transporte fora da usina.

$\mathrm{Na}$ Usina São Martinho, na época da pesquisa de campo, cerca de $30 \%$ de toda a cana transportada era do tipo cana inteira e $70 \%$, do tipo picada. Dadas as diferenças técnicas e operacionais na descarga de cana inteira e picada, a política de despacho de caminhões carregados no setor de despacho depende do tipo de caminhão, da situação das filas e da quantidade de cana descarregada nos pontos de descarga. Assim, após identificar os tipos de cana e de caminhão, o operador responsável pelo despacho determina em quais pontos de descarga determinado veículo pode descarregar. O operador deve saber identificar, pelo número de veículos em fila nos pontos de descarga e pela capacidade das moendas que são abastecidas por esses pontos, a quantidade de cana em espera e disponível para ser moída. A decisão de despacho é realizada de forma que não ocorra falta ou excesso de cana para alimentar as moendas.

Há quatro tipos de caminhões (rodotrem, treminhão, romeu e julieta e toco) com características diferentes, que podem ou não competir pelo mesmo ponto de descarga. A Tabela 1 apresenta os tipos de caminhões na Usina São Martinho, o número de caminhões de cada tipo, o tipo de cana que transportam e os pontos de descarga nas moendas por ordem de prioridade. 


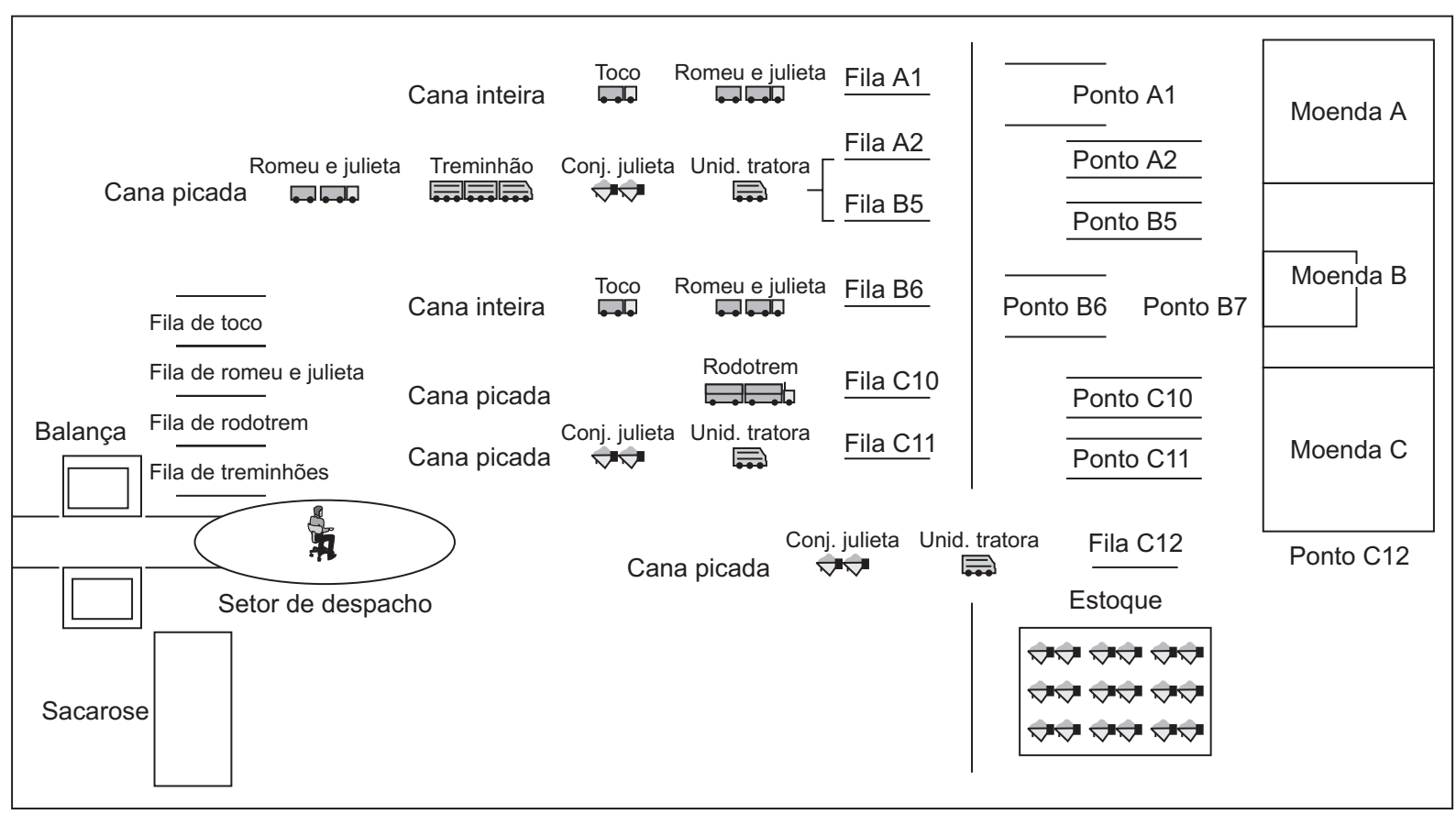

Figura 1 - Sistema de recepção de cana na usina: balança, setor de despacho e descarga.

O caminhão rodotrem transporta em média 65 toneladas de cana picada, possui um ponto específico de descarga $\left(\mathrm{C}_{10}\right.$ na moenda $\mathrm{C}$, conforme Tabela 1), e há situações em que seu descarregamento pode impedir o descarregamento de outro tipo de caminhão em um ponto adjacente ao seu (por exemplo, qualquer veículo que descarrega no ponto $\mathrm{C}_{11}$ ), sendo que tem prioridade de descarga. $\mathrm{O}$ treminhão é composto de "cavalo" e três carretas acopladas, e carrega em média 45 toneladas de cana picada. A política de despacho do treminhão depende da quantidade de caminhões de cana inteira no pátio da usina, ou seja, se há cana inteira suficiente para alimentar as moendas. Se a quantidade for suficiente, o treminhão desacopla duas carretas no estoque intermediário (Figura 1) do pátio e descarrega a carreta restante no ponto de descarga com menor fila. Se o estoque estiver completo, o treminhão espera em fila no setor de despacho com suas três carretas.
O terceiro tipo de caminhão é o romeu e julieta, que carrega em média 25 toneladas e transporta a maior parte da cana inteira da usina, além de parte da cana picada. Note, na Tabela 1 , que o romeu e julieta representa o maior número de veículos da usina (72 caminhões, ou seja, $53 \%$ ). A usina também possui, em número reduzido, caminhões do tipo toco, que carregam cana inteira. Porém, diante da atual tendência de redução de cana inteira, o número de caminhões romeu e julieta e toco vem sendo reduzido. A política de despacho para esses caminhões depende do tamanho da fila na frente dos pontos de descarga de cana inteira. Se a fila for menor que determinado número (no caso, variando de 5 a 6), o caminhão descarrega no ponto de menor fila; caso contrário, ele permanece em fila na estação de despacho. Um exemplo de regra de despacho dos caminhões é apresentado a seguir para ilustrar como essas regras estão estruturadas (as demais regras podem ser encontradas no fluxograma do Anexo). 
Tabela 1 - Tipo de caminhão e respectivos pontos de descarga nas moendas.

\begin{tabular}{lcccc}
\hline Tipo de caminhão & $\begin{array}{c}\text { Número de } \\
\text { caminhões }\end{array}$ & Tipo de cana & $\begin{array}{c}\text { Pontos de } \\
\text { descarga }\end{array}$ & Moenda \\
\hline Rodotrem & 8 & Picada & $\mathrm{C}_{10}$ & $\mathrm{C}$ \\
Treminhão & 50 & Picada & $\mathrm{C}_{11}, \mathrm{C}_{12}, \mathrm{~A}_{2}, \mathrm{~B}_{5}$ & $\mathrm{~A}, \mathrm{~B}, \mathrm{C}$ \\
Romeu e julieta (cana picada) & 60 & Picada & $\mathrm{A}_{2}, \mathrm{~B}_{5}, \mathrm{C}_{11}, \mathrm{C}_{12}$ & $\mathrm{~A}, \mathrm{~B}, \mathrm{C}$ \\
Romeu e julieta (cana inteira) & 12 & Inteira & $\mathrm{A}_{1}, \mathrm{~B}_{6}, \mathrm{~B}_{7}$ & $\mathrm{~A}, \mathrm{~B}$ \\
Toco & 6 & Inteira & $\mathrm{A}_{1}, \mathrm{~B}_{6}, \mathrm{~B}_{7}$ & $\mathrm{~A}, \mathrm{~B}$ \\
\hline
\end{tabular}

\subsection{Regra de despacho de rodotrens}

Caminhão com cana picada? Se sim, então, verifique:

Caminhão é um rodotrem? Se sim, então, verifique:

A fila à frente do ponto $\mathrm{C}_{10}$ é menor que certo limite $r$ ?

Sim, então, verifique:

Há caminhão descarregando no ponto $\mathrm{C}_{11}$ ?

Sim, então:

Espere em fila na estação despacho.

Não, então:

Descarregue no ponto $\mathrm{C}_{10}$

Não, então:

Espere em fila na estação despacho.

Conforme a Figura 1, a usina possui estoque de cana picada no pátio composto de conjuntos julieta, que correspondem às duas últimas carrocerias desacopladas do treminhão. A finalidade desse estoque intermediário é garantir que não falte cana para alimentar as moendas, caso ocorra algum problema de abastecimento de cana vinda do campo para a usina. A unidade tratora do treminhão é liberada para descarregamento logo após o desengate dos conjuntos julieta, com prioridade de descarga em relação a outros veículos (romeu e julieta e conjuntos julieta). Após a descarga nas moendas, a unidade tratora passa pelo estoque de conjuntos julieta vazios onde ocorre o engate, transformando-se em treminhão para voltar ao campo. Para mais detalhes do sistema de recepção e transporte de cana na Usina São Martinho, consulte Iannoni (2000).

\section{Simulação do sistema}

\subsection{Construção do modelo}

No setor sucroalcooleiro a simulação tem sido utilizada para investigar novas estratégias gerenciais e equipamentos, a um custo relativamente baixo para as usinas. Conforme mencionado, alguns trabalhos que utilizaram simulação para analisar sistemas desse setor podem ser encontrados em Yoshizaki (1989), Mathew \& Rajendran (1993), Hahn (1994), Lopes (1995) e Yamada (1999). Segundo Pegden et al. (1995), a simulação é "o processo de projetar um modelo de um sistema real e conduzir experimentos com esse modelo, a fim de entender seu comportamento e/ou avaliar estratégias para sua operação". Algumas das principais vantagens da simulação são (Banks, 1998): (i) possibilidade de explorar o sistema real com modificações de políticas, procedimentos, operações ou métodos, com custo relativamente baixo e sem interferir no sistema real e (ii) domínio sobre o tempo, uma vez que a simulação permite que o tempo seja reduzido no caso de fenômenos que ocorrem muito lentamente. 
Vários simuladores de fácil utilização e acompanhados por animação gráfica dinâmica do sistema estão disponíveis no mercado, entre eles o software Arena, utilizado no presente trabalho. Outros detalhes sobre o Arena podem ser encontrados em Smc (1994), Costa (1997) e Kelton et al. (1998).

Os dados foram coletados na Usina São Martinho em dias considerados típicos do meio da safra (junho). Os dados coletados na balança correspondem ao tipo de cana, ao tipo de caminhão, ao número do caminhão, à carga transportada por cada caminhão, à origem da cana (própria ou de terceiros) e aos instantes de entrada e saída de cada caminhão do sistema de recepção de cana. Os dados foram analisados pelo software estatístico Best-Fit (PC, 1996). Foram obtidos histogramas e medidas descritivas e realizados testes de aderência para determinação das distribuições estatísticas que melhor representam os dados. As distribuições encontradas e utilizadas na simulação estocástica como dados de entrada representam o tempo médio de viagem de cada tipo de caminhão ao campo. A Figura 2 é um exemplo da análise gráfica do Best-Fit: o histograma representa os dados coletados e a curva, a distribuição teórica do tempo de viagem de treminhões ao campo. Outros detalhes dessa e de demais análises estatísticas são apresentados em Iannoni (2000).

O modelo de simulação construído no Arena teve por objetivo representar a trajetória dos veículos desde a entrada na balança até a saída das moendas (conforme Figura 1). Foram desconsiderados tempos de pesagem (ordem de segundos) e testes no laboratório de sacarose para os veículos sorteados, dado que não eram significativos para o tempo médio total das operações no pátio de descarga. Os tempos de deslocamento de uma estação à outra (por exemplo, da balança à estação despacho, e da estação despacho às estações de descarga) foram estimados de acordo com as informações e os dados coletados na usina. Os tempos gastos com manutenção e abastecimento dos caminhões foram incluídos nos tempos de viagem, pois os dados foram coletados a partir da saída dos caminhões das moendas.

Nesse modelo, o sistema de recepção de cana na usina é considerado sistema fechado. Após serem pesados na balança, os veículos descarregam a cana no pátio da usina, em seguida, dirigem-se ao campo e depois retornam carregados para a balança. Assim, a taxa média de chegada de veículos na usina não corresponde a um dado de entrada, mas é resultado do modelo de simulação determinado pelo tempo de ciclo total dos caminhões.

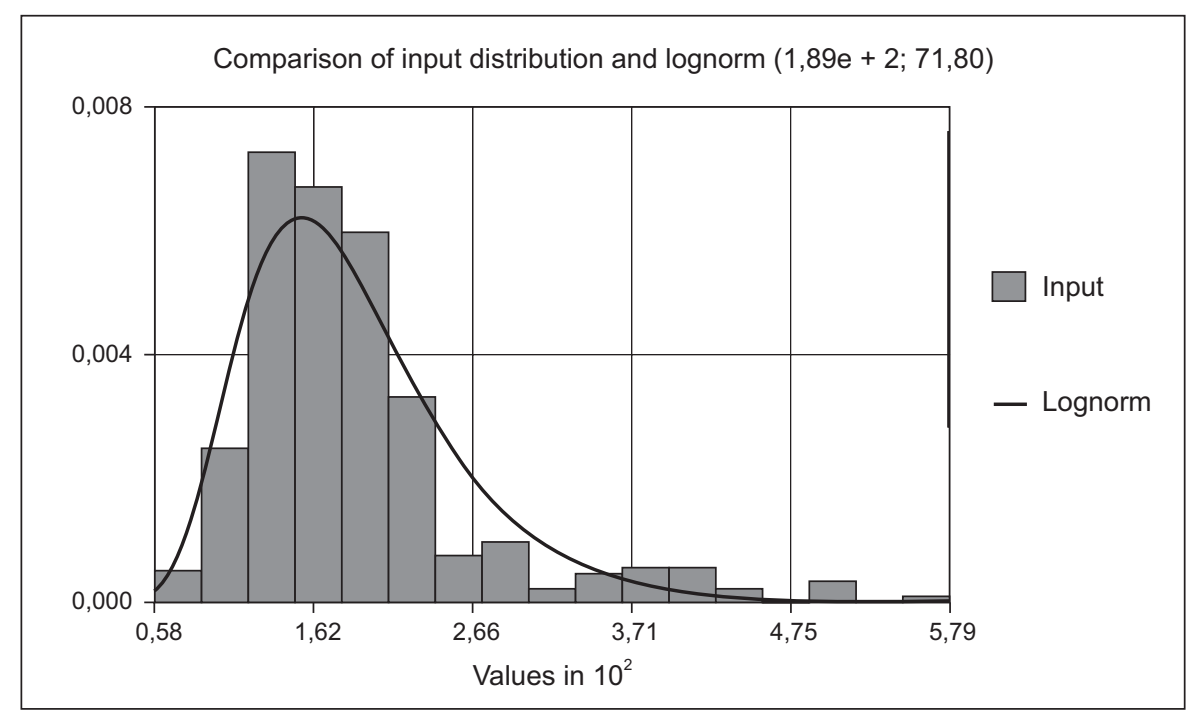

Figura 2 - Tempo de viagem de caminhões treminhões ao campo. 
Tabela 2 - Parâmetros utilizados nas regras de despacho.

\begin{tabular}{|c|c|c|}
\hline Parâmetro & Representa & \\
\hline$L$ & Número máximo de conjuntos em estoque & 32 \\
\hline$m$ & Número máximo de veículos à frente dos pontos $\mathrm{A}_{2} \mathrm{e} \mathrm{B}_{5}$ & 2 \\
\hline$n$ & $\begin{array}{l}\text { Número mínimo de veículos à frente do ponto } \mathrm{A}_{1} \text { que garanta alimentação } \\
\text { da moenda } \mathrm{A} \text { sem que ocorra falta de cana inteira }\end{array}$ & 3 \\
\hline$n$ ' & $\begin{array}{l}\text { Número mínimo de veículos à frente do ponto } \mathrm{B}_{6} \text { que garanta alimentação } \\
\text { da moenda } \mathrm{B} \text { sem que ocorra falta de cana inteira }\end{array}$ & 2 \\
\hline$q$ & Número máximo de veículos à frente dos pontos de cana inteira $\left(\mathrm{A}_{1}\right.$ e $\left.\mathrm{B}_{6}\right)$ & 5 \\
\hline$p$ & Número máximo de veículos à frente do ponto $\mathrm{C}_{10}$ (rodotrens) & 1 \\
\hline$r$ & Número máximo de veículos à frente do ponto $\mathrm{C}_{11}$ & 2 \\
\hline$t$ & Número máximo de veículos à frente do ponto $\mathrm{C}_{12}$ & 1 \\
\hline
\end{tabular}

Esse tempo de ciclo é a soma dos tempos de permanência no sistema de descarga e de viagem ao campo, carregamento e retorno à usina.

A partir dos dados coletados e do modelo de simulação, a média de chegada de cada tipo de caminhão pôde ser obtida de duas formas: utilizando (i) uma variável que conta a diferença entre o instante de chegada de um caminhão e o instante de chegada de seu antecessor do mesmo tipo e (ii) o número de viagens realizadas por tipo de caminhão no período considerado.

Inicialmente, os parâmetros utilizados para as regras de despacho, as quais determinam o número-limite em fila e no estoque, respeitaram o que ocorre no sistema em funcionamento normal. Assim, o modelo foi construído como se as regras de operação fossem respeitadas com rigor, considerando a prioridade dos veículos e as especificidades dos sistemas de descarga.

Para outros detalhes do modelo de simulação, consulte o fluxograma do Anexo, que mostra como o modelo foi estruturado de acordo com a política de despacho da usina. Os parâmetros $L, m, n, n$ ', $q, p, r$ e $t$, cujos significados são apresentados na Tabela 2, representam o tamanho da fila nos pontos de descarga ou o tamanho de estoque, e são determinados pela política operacional do sistema em um dia típico de operação. Os responsáveis pelo estabelecimento desses valores são operadores e tomadores de decisão do sistema.

\subsection{Validação do modelo}

De acordo com Shannon (1975) e Banks (1998), o principal objetivo da validação é garantir que os pressupostos e as simplificações adotadas do sistema real sejam razoáveis e estejam corretamente implementados. Essa validação foi realizada de duas formas: (i) consultas com especialistas que conhecem bem o sistema de recepção de cana da Usina São Martinho e podem avaliar se os resultados obtidos são consistentes e (ii) simulação via leitura dos dados coletados e comparação com o histórico de algumas medidas de desempenho coletadas em um dia considerado típico de funcionamento do sistema. Note que não se trata de simulação estocástica (utilizando distribuições estatísticas para representar os dados), realizada a seguir (Seção 4), mas de uma simulação que apenas lê os dados de quantidade de cana transportada, chegada e saída dos veículos nos dias amostrados (via o Read do Arena), e a partir deles reproduz a operação do sistema aplicando as regras definidas no modelo. Para dar início à simulação e inicializar as variáveis, foi utilizado um período de warm-up de 1.440 minutos. Os resultados dessa simulação foram comparados com as medidas que puderam ser computadas a partir das planilhas dos dados coletados: (i) tempo médio de permanência no sistema de descarga para cada tipo de caminhão, (ii) taxa média de chegada de veículos por minuto e (iii) quantidade média de cana que entra e sai da usina diariamente. 
O modelo de simulação representa o sistema, considerando que as regras operacionais deste sejam executadas de forma contínua pelos operadores e pelos equipamentos no processo de descarga. Porém, na prática, sabe-se que há outros aspectos que influem na maneira de agir de operadores e tomadores de decisão. Isso ocorre principalmente em sistema contínuo e complexo, como o sistema de recepção de cana da Usina São Martinho, em que podem ocorrer: quebra de máquinas, problemas industriais e agrícolas, interrupções para mudanças das frentes de colheita, acidentes que interrompem o livre trânsito de veículos no pátio e muitos outros. Esses fatores, aliados às simplificações do modelo comentadas na Seção 3.1, são responsáveis pelas diferenças encontradas entre os resultados obtidos na prática (calculados diretamente das planilhas de dados coletados) e os obtidos com o modelo de simulação no Arena. A Tabela 3 apresenta essa comparação em termos das medidas (i), (ii) e (iii) citadas anteriormente. Nota-se que as diferenças obtidas (por exemplo, um desvio do tempo médio geral de permanência no sistema de pouco mais de 2 minutos, ou seja, 9\% em relação à amostra) são razoáveis se for considerado o fato de as regras de despacho impostas ao modelo de simulação não serem, na prática, seguidas com absoluto rigor. Assim, admite-se que as simplificações são aceitáveis e, dessa forma, considera-se o modelo validado.

Tabela 3 - Comparação entre medidas simuladas e medidas obtidas pela amostra.

\begin{tabular}{lccc}
\hline \multicolumn{1}{c}{$\begin{array}{c}\text { Tempo médio de permanência } \\
\text { no sistema (min) }\end{array}$} & Amostra & Simulação de dados & Desvio p/ amostra \\
\hline Média geral & 24,3 & 22,1 & $-9,0 \%$ \\
Rodotrem & 14,2 & 11,7 & $-17,6 \%$ \\
Treminhões & 14,7 & 15,8 & $7,3 \%$ \\
Romeu e julieta (cana inteira) & 30,5 & 25,7 & $-15,7 \%$ \\
Romeu e julieta (cana picada) & 20,7 & 22,8 & $10,1 \%$ \\
Toco & 21,0 & 20,4 & $-2,8 \%$ \\
\hline Taxa média de chegada (veículos/min) & Amostra & Simulação de dados & Desvio p/ amostra \\
\hline Rodotrem & 0,057 & 0,060 & $5,2 \%$ \\
Treminhões & 0,220 & 0,225 & $2,2 \%$ \\
Romeu e julieta (cana inteira) & 0,280 & 0,290 & $3,6 \%$ \\
Romeu e julieta (cana picada) & 0,082 & 0,085 & $3,7 \%$ \\
Toco & 0,022 & 0,020 & $-9,1 \%$ \\
\hline Quantidade média de cana (t/dia) & Amostra & Simulação de dados & Desvio p/ amostra \\
\hline Total de cana transportada & $31.959,6$ & $32.157,4$ & $0,6 \%$ \\
Total de cana descarregada & $31.953,9$ & $32.153,5$ & $0,6 \%$ \\
\hline
\end{tabular}




\section{Simulação estocástica}

\subsection{Hipóteses do modelo de simulação estocástica}

A simulação estocástica é realizada utilizando distribuições estatísticas para representar os dados de entrada. Foi analisado um sistema nãoterminal, pois no período da safra as operações de transporte e moagem de cana na Usina São Martinho ocorrem continuamente durante 24 horas, 7 dias por semana. Foi verificado, a partir da análise gráfica dos dados obtidos, que a chegada de caminhões na usina não sofre grandes flutuações ao longo do dia. Em um dia típico, sem maiores problemas operacionais, a chegada total de veículos ocorre de forma razoavelmente uniforme. Assim, são consideradas as seguintes hipóteses no modelo de simulação estocástica:

1. Trata-se de um sistema fechado em que o tempo médio total que os veículos permanecem no campo (viagem de ida e volta, tempo de espera e processo de carregamento na frente de corte de cana) é representado por uma distribuição de probabilidade, para cada tipo de veículo, determinada a partir dos dados coletados em um dia típico de operações (veja Seção 3.2). Considera-se, dessa forma, que, em média, a distância entre os talhões de colheita e as condições operacionais de corte, carregamento e transporte se mantenham no período de safra.

2. O processo de viagem e carregamento no campo é considerado independente entre os veículos. Portanto, cada veículo permanece no campo um tempo determinado pela distribuição de probabilidade, a qual depende do tipo do veículo. Na prática, há dependência entre os veículos, principalmente no processo de carregamento. Por exemplo, se quebrar uma máquina em uma frente de colheita, haverá formação de filas de veículos fora da usina, o abastecimento de cana será prejudicado e aumentará o tempo de ciclo externo dos veículos que se dirigem para aquela frente.
3. O tempo de moagem depende da capacidade de cada moenda e da carga transportada por veículo. Considera-se que as moendas possam operar com total capacidade sem interrupções. Na prática, as interrupções na moagem não ocorrem com freqüência significativa, pois uma parada nas moendas pode resultar em sérios problemas para a produção contínua de açúcar e álcool.

\subsection{Cálculo da fase transiente e do tempo total de simulação}

Para calcular a fase transiente da simulação estocástica foi utilizada a ferramenta OutPut Analyser, que é parte do Arena. Essa ferramenta fornece o gráfico da média móvel dos dados obtidos em uma longa rodada de simulação (por exemplo, 20 dias). Por meio da análise desse gráfico, pode-se determinar o período transiente. Realizando esse procedimento para as principais medidas dessa simulação, concluiu-se que o tempo de fase transiente deve ser de 3.000 minutos (50 horas).

Para determinar o tempo da simulação utilizouse o Método de Loteamento (Law \& Kelton, 1991; Pegden et al., 1995). Por esse método, o OutPut Analyser realiza os procedimentos estatísticos necessários, calculando a correlação para diferentes tamanhos de lote e realizando o loteamento a partir da determinação do número de observações de cada lote que garanta correlação próxima de zero entre estes.

Para determinar o tempo dessa simulação foi escolhida uma medida como resultado da simulação (no caso, o tempo médio de permanência em estoque) que apresenta maior correlação entre as observações de lotes. Assim, o número de observações de cada lote garante correlação próxima de zero para esta e para as demais medidas.

O tempo da simulação foi determinado da seguinte forma: sejam $n$ o número de observações em cada lote, $m$ o número de lotes para determinar o intervalo de confiança, $T_{t}$ o tempo total de simulação e $T_{s}$ o tempo de fase transiente. 
Pelo cálculo de correlação verificou-se que esta é muito próxima de zero para lotes com $n=$ 40 observações. De acordo com Pedgen et al. (1995), o número $n$ deve ser multiplicado por 10 (coeficiente de segurança), ou seja, $n$ passa a ser 400 observações. Considera-se $m=20$ representando o número de lotes. No caso da medida tempo médio de permanência em estoque, há uma observação a cada 7,03 minutos. Dessa forma, o tempo total de simulação $T_{t}$ é dado pela seguinte regra de três:

$$
\begin{aligned}
& \begin{array}{c}
20 \text { lotes } \times 400 \\
\text { observações }(m \times n)
\end{array} \\
& \qquad \begin{array}{l}
\text { observação } \\
\text { Logo, } y=56.240 \text { minutos; } T_{t}=T_{S}+y=3.000+
\end{array} \\
& +56.240=59.240 \text { minutos }=987,33 \text { horas } \\
& \text { O tempo computacional para realizar a } \\
& \text { simulação estocástica foi de } 3,17 \text { minutos em } \\
& \text { um microcomputador Pentium II-345 } \mathrm{MH}_{Z} \text {. No } \\
& \text { OutPut Analyser foi calculado o intervalo de } \\
& \text { confiança de cada medida analisada. Os } \\
& \text { resultados dessa simulação podem ser com- } \\
& \text { parados com os valores obtidos da amostra, por } \\
& \text { exemplo, o tempo médio de permanência no } \\
& \text { sistema para os caminhões em geral e o total de } \\
& \text { cana descarregada em média por dia são } 21,5 \\
& \text { min e 34.009,7 t, ou seja, apresentam desvios } \\
& \text { de -11,5\% e 6,4\%, respectivamente, em relação } \\
& \text { aos da amostra (24,3 min e 31.953,9 t, conforme } \\
& \text { Tabela 3). Os resultados mostram que a simu- } \\
& \text { lação estocástica, por ser analisada durante um } \\
& \text { período contínuo (vários dias), considerando as } \\
& \text { simplificações e as hipóteses comentadas ante- } \\
& \text { riormente, e em razão de seu caráter aleatório, } \\
& \text { traz alguns desvios em relação aos resultados } \\
& \text { médios de dados de um dia típico de operação } \\
& \text { (amostra). Apesar disso, são aceitáveis e podem } \\
& \text { ser utilizados para medir o desempenho do } \\
& \text { sistema. }
\end{aligned}
$$

\subsection{Escolha de medidas de desempenho e resultados obtidos}

Como um dos objetivos deste trabalho é comparar as medidas analisadas no cenário original com as de outros cenários alternativos, o fato de haver muitas medidas de desempenho como resultados da simulação estocástica dificulta a comparação. É necessário encontrar medidas de desempenho mais agregadas que possibilitem apontar a alternativa que apresenta o melhor desempenho ou se nas alternativas testadas há uma que possa superar o desempenho do sistema original.

As medidas consideradas importantes pelos tomadores de decisão da Usina São Martinho estão relacionadas principalmente aos tempos médios de espera dos caminhões no pátio da usina. Isso porque nesses tempos poderiam estar sendo utilizados na rodovia ou no campo carregando cana. $\mathrm{O}$ aumento da utilização média dos caminhões poderia implicar redução da frota, do número de motoristas, do consumo de combustível etc. Mas o custo de espera para cada tipo de caminhão não pode ser relacionado apenas ao tempo de espera; também é necessário considerar que cada caminhão tem uma taxa média de chegada e transporta determinada quantidade média de cana. Assim, os caminhões devem ter custos diferenciados para uma unidade de tempo de espera média no pátio. Por exemplo, não se pode considerar que o custo de um minuto de espera de um rodotrem (capacidade média de 65 t) seja o mesmo que o de um romeu e julieta (capacidade média de $25 \mathrm{t}$ ).

Diante dessas considerações, uma medida interessante para analisar o desempenho do sistema de recepção de cana na usina é relacionar o tempo médio de espera de cada caminhão com sua taxa média de chegada no sistema e a quantidade média de cana transportada por viagem. Dessa forma, deve ser medida a quantidade média de cana em espera nas filas ao longo do tempo. A comparação dos cenários testados tem por objetivo encontrar aquele que apresente o mínimo valor dessa medida.

A quantidade média de cana em espera nas filas, $Q_{i}$, para cada tipo de caminhão, $i$, pode ser calculada por:

$$
Q_{i}=W_{i} \lambda_{i} q_{i}, \text { em que: }
$$

$W_{i}=$ tempo médio de espera no sistema para o caminhão do tipo $i$ (unidade de tempo); 
$\lambda_{i}=$ taxa de chegada do caminhão do tipo $i$ no sistema (caminhões por unidade de tempo);

$q_{i}=$ quantidade média de cana transportada pelo caminhão do tipo $i$ (quantidade de cana por caminhão).

Em cada possível configuração do sistema, essa medida é calculada para todos os caminhões, obtendo, assim, o valor da quantidade total de cana em espera nas filas:

$$
Q=\sum_{i} Q_{i}
$$

que serve de base para a escolha da melhor alternativa. Outra medida importante a ser considerada na avaliação do desempenho do sistema é a quantidade média de cana descarregada por dia, sendo que a usina possui certa capacidade de moagem que deve ser respeitada. No caso da Usina São Martinho, essa capacidade é de 36.000 t/dia (mais de 1.000 viagens de caminhões por dia).

Portanto, os cenários que se aproximam mais da capacidade máxima de moagem apresentam melhor desempenho, pois a política de despacho utilizada resulta em melhor aproveitamento da capacidade das moendas.

A Tabela 4 apresenta o tempo médio de permanência no sistema $\left(W_{i}\right)$, a taxa média de chegada $(\lambda)$, a quantidade média de cana por viagem $\left(q_{i}\right)$ e a quantidade média de cana em espera $\left(Q_{i}\right)$ para cada tipo de caminhão no cenário original. Além disso, apresenta a quantidade média em espera total $(Q=508,2 \mathrm{t})$ e a quantidade média de cana descarregada por dia $(34.009,7$ t). Esses valores são comparados com os valores obtidos nos cenários alternativos explorados na próxima seção.

Para tornar a análise mais acurada, os caminhões treminhões foram divididos em:

1. Inteiro: corresponde ao treminhão que não desengata no estoque, descarrega suas três carretas na moenda e depois retorna ao campo com elas vazias.

2. Unidade tratora: corresponde ao treminhão que deixou seu conjunto julieta (duas últimas carretas) no estoque do pátio. Com apenas uma carreta, esse veículo descarrega na moenda e depois engata a um conjunto julieta vazio antes de retornar ao campo.

Tabela 4 - Cálculo da quantidade média de cana em espera.

\begin{tabular}{lcccc}
\hline \multicolumn{1}{c}{ Tipo de caminhão $\left(_{i}\right)$} & $\begin{array}{c}\text { Tempo médio } \\
\text { sistema (min) } \\
\left(\boldsymbol{W}_{\boldsymbol{i}}\right)\end{array}$ & $\begin{array}{c}\text { Taxa de cheg. } \\
\text { veic./min } \\
\left(\boldsymbol{\lambda}_{\boldsymbol{i}}\right)\end{array}$ & $\begin{array}{c}\text { Quant. cana p/ } \\
\text { viagem }(\mathbf{t}) \\
\left(\boldsymbol{q}_{\boldsymbol{i}}\right)\end{array}$ & $\begin{array}{c}\text { Quant. média } \\
\text { espera }(\mathbf{t}) \\
\left(\boldsymbol{Q}_{i}\right)\end{array}$ \\
\hline Rodotrem & 13,0 & 0,059 & 65 & 49,8 \\
Treminhão inteiro & 19,9 & 0,095 & 45 & 85,1 \\
Unidade tratora & 18,6 & 0,148 & 15 & 41,3 \\
Conjunto julieta & 28,9 & 0,148 & 30 & 128,3 \\
Romeu e julieta (c. inteira) & 22,9 & 0,258 & 25 & 147,7 \\
Romeu e julieta (c. picada) & 23,1 & 0,086 & 25 & 49,7 \\
Toco & 22,1 & 0,019 & 15 & 6,3 \\
Total $(Q)$ & & & & 508,2 \\
\hline
\end{tabular}

Quantidade média de cana (t/dia)

$34.009,75$ 
3. Conjunto julieta: corresponde ao conjunto das duas carretas cheias deixadas no estoque do pátio, as quais são depois rebocadas por tratores para descarregamento na moenda.

Os tempos médios de permanência no sistema de treminhões inteiros e de unidades tratoras são bem próximos (19,9 e 18,6 min, respectivamente), mesmo sendo o treminhão inteiro um veículo três vezes maior que a unidade tratora. Isso porque os treminhões inteiros descarregam sem desengatar somente se o sistema estiver vazio, ou seja, com pouca cana no pátio para abastecer a moenda. Como precisam ser rapidamente despachados para abastecer as moendas, esses veículos apresentam, em média, maior tempo de processamento e menor tempo de fila do que os demais (pois não "entram" no sistema quando há congestionamento).

Outras medidas interessantes de serem analisadas são apresentadas nas Tabelas 5 e 6. A Tabela 5 apresenta os resultados para as medidas relacionadas aos conjuntos julieta. $\mathrm{O}$ estoque de conjuntos julieta (média de 9,2) é composto por veículos cheios deixados no pátio após o desengate do treminhão e que esperam ordem de despacho. O estoque de conjuntos vazios (média de 20,3) é composto pelos conjuntos julieta que descarregaram e estão em fila à espera de uma unidade tratora para engate e retorno ao campo.

Além dos conjuntos julieta que se encontram acoplados compondo o treminhão, é preciso considerar os conjuntos julieta reservas, que permanecem no pátio em estoque cheios ou vazios à espera das unidades tratoras para engate e retorno ao campo em forma de treminhão. $\mathrm{Na}$ simulação, o conjunto reserva é criado quando uma unidade tratora não encontra um conjunto vazio disponível para engatar e retornar ao campo. O número máximo de conjuntos criados (29, conforme Tabela 5) garante o retorno do treminhão ao campo sem ocorrer filas de unidades tratoras vazias após a descarga. Em relação ao número de tratores rebocadores ocupados, observa-se na Tabela 5 que o número médio é 1,8 e o número máximo requisitado é de 3 tratores. $\mathrm{O}$ número de tratores ocupados corresponde ao número de conjuntos julieta que estão em fila ou em processo nos pontos de descarga.

A Tabela 6 apresenta a quantidade média de cana descarregada por hora. Lembrando que as moendas $\mathrm{A}, \mathrm{B}$ e $\mathrm{C}$ possuem capacidades de 450,450 e $600 \mathrm{t} / \mathrm{h}$, respectivamente, pode-se verificar que os resultados obtidos na tabela $(435,5,435,5$ e 548,3 t/h) estão próximos dessas capacidades, com taxas médias de ocupação de 0,96, 0,96 e 0,92. A quantidade descarregada de cana picada $(1.003,2 \mathrm{t} / \mathrm{h})$ corresponde a cerca de $70,6 \%$ do total.

\section{Cenários alternativos}

Os resultados obtidos na simulação estocástica mostram que o modelo é capaz de representar satisfatoriamente o funcionamento do sistema de descarga de cana. Uma aplicação interessante do modelo é analisar cenários alternativos e compará-los com o cenário atual. Por ilustração, a seguir analisam-se três cenários.

Tabela 5 - Medidas relacionadas ao estoque de conjuntos julieta.

\begin{tabular}{lccc}
\hline \multicolumn{1}{c}{ Medida } & Média & Média dos mínimos & Média dos máximos \\
\hline Número de conjuntos julieta em estoque & 9,2 & 5,3 & 22,6 \\
Número de conjuntos julieta vazios - fila & 20,3 & 6,7 & 28,1 \\
Número de conjuntos julieta reserva & - & - & 29,0 \\
Tempo de estoque no pátio (min) & 64,9 & 20,3 & 91,4 \\
Número de tratores ocupados & 1,8 & 0,9 & 2,6 \\
\hline
\end{tabular}


Tabela 6 - Quantidade média de cana descarregada por hora (t/h).

\begin{tabular}{lccc}
\hline & Média & Média dos mínimos & Média dos máximos \\
\hline Moenda A & 435,5 & 412,1 & 442,0 \\
Moenda B & 435,8 & 415,3 & 445,2 \\
Moenda C & 548,3 & 521,0 & 562,1 \\
Cana picada & $1.003,2$ & 766,7 & $1.106,1$ \\
Cana inteira & 416,2 & 401,3 & 466,3 \\
\hline
\end{tabular}

\subsection{Cenário 1}

O cenário 1 considera que todos os treminhões desengatam seus conjuntos julieta no estoque do pátio. As regras de despacho dos conjuntos julieta em estoque para descarga nas moendas mudam a fim de manter a rotatividade do estoque. Não são consideradas limitações de estoque ou possibilidade de treminhões inteiros descarregarem na moenda A ou B para suprir falta de cana inteira.

Essa alteração é motivada pela hipótese de que com mais unidades tratoras e conjuntos julieta os veículos sejam melhor distribuídos entre os pontos de descarga, de maneira a reduzir o tempo médio de permanência do treminhão na usina. $\mathrm{O}$ estudo deste cenário também se justifica por se tratar de uma alteração simples e de baixo custo, já que não envolve aumento de pontos de descarga e alterações na frota de veículos.

A Tabela 7 compara os resultados obtidos com os do cenário original. Observam-se reduções significativas nos tempos médios de permanência dos caminhões romeu e julieta (cana inteira) e toco $(27,9 \%$ e $21,7 \%$, respectivamente). Isso ocorre porque a falta de caminhões treminhões inteiros, que no cenário original descarregam nos pontos de descarga de cana picada, disponibiliza a moenda para receber os caminhões com cana inteira em seus respectivos pontos, reduzindo o tempo de fila desses veículos.

Ressalta-se que o tempo médio de permanência da unidade tratora não sofreu alteração significativa (aumento de apenas 1,9\%). Isso porque, com maior quantidade de unidades tratoras no sistema, os veículos tendem a esperar também mais tempo em fila, sendo este relativamente maior do que o tempo de moagem de sua carga.

Em relação à taxa média de chegada na usina, há aumento substancial da taxa de chegadas de unidades tratoras e conjuntos julieta $(60 \%$ para ambos), o que é esperado dado que só ocorrem desengates. A quantidade total média de cana em espera é de 439,4 t (13,5\% menor que a do cenário original) e a quantidade média de cana descarregada é de 34.392,4 t (apenas 1,1\% maior que a do cenário original). Pode-se concluir que, neste cenário, há maior aproveitamento das moendas, principalmente das moendas A e B, com a nova política de despacho de treminhões. Um dos prováveis fatores que contribuiu para esse resultado é que, quando há pouca cana a ser descarregada na usina (pontos com pequenas filas), os conjuntos julieta podem cobrir essa falta de forma mais eficiente que os treminhões, o que reduz os períodos de ociosidade das moendas e aumenta a quantidade de cana descarregada. As porcentagens de ocupação das moendas A, B e C são $93 \%, 96 \%$ e $97 \%$, respectivamente.

Observa-se, portanto, que uma alteração relativamente simples na política de despacho, que não requer aumento no número de servidores ou da frota de caminhões, pode trazer contribuições significativas para o sistema de recepção de cana dessa usina.

\subsection{Cenário 2}

A Usina São Martinho tende a aumentar o número de caminhões rodotrens nas operações de transporte e descarga, pois esses veículos transportam maior quantidade de cana com mais segurança. 
Iannoni \& Morabito - Análise do Sistema Logístico de Recepção de Cana-de-açúcar: Um Estudo de Caso Utilizando...

Tabela 7 - Resultados obtidos para o cenário 1 e comparados com os do cenário original.

\begin{tabular}{lcccccc}
\hline \multicolumn{1}{c}{ Tipo de caminhão } & $\begin{array}{c}\text { Tempo médio } \\
\text { sistema (min) }\end{array}$ & $\begin{array}{c}\text { Desvio } \\
(\boldsymbol{\%})\end{array}$ & $\begin{array}{c}\text { Taxa de cheg. } \\
\text { veic./min }\end{array}$ & $\begin{array}{c}\text { Desvio } \\
(\boldsymbol{\%})\end{array}$ & $\begin{array}{c}\text { Quant. cana p/ } \\
\text { viagem (t) }\end{array}$ & $\begin{array}{c}\text { Quant. média } \\
\text { espera (t) }\end{array}$ \\
\hline Rodotrem & 13,7 & $5,4 \%$ & 0,059 & $0,0 \%$ & 65 & 52,5 \\
Treminhão inteiro & - & & - & - & - & - \\
Unidade tratora & 20,8 & $1,9 \%$ & 0,237 & $60,0 \%$ & 15 & 73,9 \\
Conjunto julieta & 20,6 & $-2,9 \%$ & 0,237 & $60,0 \%$ & 30 & 146,5 \\
Romeu e julieta (c. int.) & 16,5 & $-27,9 \%$ & 0,263 & $2,0 \%$ & 25 & 108,5 \\
Romeu e julieta (c. pic.) & 24,6 & $6,5 \%$ & 0,086 & $0,0 \%$ & 25 & 52,9 \\
Toco & 17,3 & $-21,7 \%$ & 0,020 & $5,2 \%$ & 15 & 5,1 \\
Total & & & & & & 439,4 \\
\hline
\end{tabular}

Quantidade média de cana (t/dia)

$34.392,4$

O objetivo do cenário 2 é analisar os benefícios do aumento em $50 \%$ (8 para 12) no número de rodotrens no sistema, em substituição a um número proporcional de treminhões. Assim, o cenário considera a redução na frota de treminhões para compensar o aumento de cana descarregada pelo maior número de rodotrens, caso contrário, o sistema não seria capaz de absorver o aumento de cana transportada em razão da limitação de capacidade das moendas.

A redução no número de treminhões é proporcional à quantidade de cana descarregada. Este cenário também inclui um ponto específico de descarga para absorver o aumento de rodotrens, instalado na moenda $\mathrm{A}$.

Deve-se considerar uma nova distribuição dos pontos de descarga, de forma que a quantidade média de cana descarregada em cada moenda se aproxime de sua capacidade. Considera-se também que o rodotrem não tem mais prioridade sobre a unidade tratora, caso contrário, o aumento do número de rodotrens tenderia a reduzir o fluxo de treminhões, dado que as unidades tratoras e os conjuntos julieta esperam maior tempo no pátio de descarga. Assim, a alimentação dos pontos de descarga é realizada da seguinte forma:
- A moenda A é alimentada pelos pontos $\mathrm{A}_{3}$ (novo ponto específico para descarga de rodotrens) e $\mathrm{A}_{2}$ (ponto de descarga de veículos com cana picada se ocorrer falta de rodotrens descarregando no ponto $\mathrm{A}_{3}$ ).

- A moenda B é alimentada com a cana inteira que chega à usina por intermédio dos pontos $A_{1}$ (no cenário original pertence à moenda $\mathrm{A}$ ), $\mathrm{B}_{5}$ (onde há descarga de cana picada), $\mathrm{B}_{6}$ e $\mathrm{B}_{7}$ (que permanecem alimentando essa moenda com cana inteira, como no cenário original).

- A moenda C é alimentada com os mesmos pontos do cenário original, ou seja, os pontos $\mathrm{C}_{10}, \mathrm{C}_{11}$ e $\mathrm{C}_{12}$.

A redução no número de treminhões é feita pela compensação da quantidade de cana descarregada da forma $\Delta \mathrm{Q}_{\mathrm{R}} \cong \Delta \mathrm{Q}_{\mathrm{T}}$, em que:

$\Delta \mathrm{Q}_{\mathrm{R}}$ : aumento da quantidade média de cana transportada por rodotrens.

$\Delta \mathrm{Q}_{\mathrm{T}}$ : redução da quantidade média de cana transportada por treminhões.

$\Delta \mathrm{Q}_{\mathrm{R}}$ : (aumento do número de rodotrens) x (número médio de viagens por dia por rodotrem) $x$ (quantidade média de carga por viagem por veículo) $=4 \times 10,5 \times 65=2.730 \mathrm{t} / \mathrm{dia}$. A definição de $\Delta \mathrm{Q}_{\mathrm{T}}$ é similar. Logo: 
Redução do número de treminhões $\cong \Delta \mathrm{Q}_{\mathrm{T}} /$ (número médio de viagens por dia por treminhão)/ (quantidade de cana por viagem por treminhão) $\cong$ $\frac{2.730}{45 \times 7,26}=8,36$, ou seja, 9 treminhões.

Pode-se observar pelos resultados da Tabela 8 que, em relação ao tempo médio de permanência no sistema, somente a unidade tratora apresenta menor tempo médio de espera no pátio $(-32 \%)$ do que o cenário original. Esse resultado pode ser explicado por dois fatores: a redução na quantidade de treminhões na usina e a perda da prioridade do rodotrem em relação às unidades tratoras. Convém lembrar que a unidade tratora, desde o cenário original, tem prioridade em relação a outros veículos de cana picada, com exceção do rodotrem. O aumento no tempo médio dos demais veículos pode ser explicado pelo aumento de rodotrens com prioridade em relação a outros veículos com cana picada e inteira (com exceção da unidade tratora) e pela limitação de capacidade das moendas. Em particular, o aumento de $40 \%$ no tempo médio de espera para o rodotrem ocorre em razão do aumento da quantidade desses veículos e da perda de prioridade para a unidade tratora.

Observa-se que para todos os veículos, exceto o rodotrem, ocorre redução na taxa média de chegada na usina. $\mathrm{O}$ aumento da taxa de chegada de rodotrens $(31,4 \%)$ se deve ao aumento de $50 \%$ no número desses veículos. Nota-se também significativa redução na taxa de treminhões inteiros $(-87,4 \%)$, causada pela menor freqüência de desengates, dado que o sistema é bem alimentado com cana picada em razão do aumento de rodotrens. A quantidade média de cana em espera no pátio, para este cenário, é de 599,3 t, representando aumento de $18 \%$ em relação ao cenário original. Esse resultado mostra que o aumento no número de veículos de determinado tipo (por exemplo, rodotrem), apesar da redução proporcional de outro tipo de veículo (treminhão), pode gerar maior quantidade de cana em espera para ser moída, devido à capacidade limitada das moendas.

Tabela 8 - Resultados obtidos para o cenário 2 e comparados com os do cenário original.

\begin{tabular}{lcccccc}
\hline \multicolumn{1}{c}{ Tipo de caminhão } & $\begin{array}{c}\text { Tempo } \\
\text { médio } \\
\text { sistema (min) }\end{array}$ & $\begin{array}{c}\text { Desvio } \\
(\boldsymbol{\%})\end{array}$ & $\begin{array}{c}\text { Taxa de } \\
\text { cheg. } \\
\text { veic./min }\end{array}$ & $\begin{array}{c}\text { Desvio } \\
(\%)\end{array}$ & $\begin{array}{c}\text { Quant. cana } \\
\text { p/ viagem (t) }\end{array}$ & $\begin{array}{c}\text { Quant. } \\
\text { média } \\
\text { espera (t) }\end{array}$ \\
\hline Rodotrem & 18,2 & $40,0 \%$ & 0,086 & $31,4 \%$ & 65 & 101,7 \\
Inteiro & 22,7 & $14,1 \%$ & 0,012 & $-87,4 \%$ & 45 & 12,3 \\
Unidade tratora & 12,6 & $-32,0 \%$ & 0,206 & $-28,1 \%$ & 15 & 38,9 \\
Conjunto julieta & 34,1 & $17,9 \%$ & 0,206 & $-28,1 \%$ & 30 & 210,7 \\
Romeu e julieta (c. int.) & 27,5 & $20,1 \%$ & 0,252 & $-2,3 \%$ & 25 & 173,2 \\
Romeu e julieta (c. pic.) & 28,1 & $21,6 \%$ & 0,082 & $-4,6 \%$ & 25 & 57,6 \\
Toco & 23,2 & $5,0 \%$ & 0,014 & $-26,3 \%$ & 15 & 4,9 \\
Total & & & & & & 599,3 \\
\hline
\end{tabular}

Quantidade média de cana (t/dia) 
A quantidade média de cana descarregada por dia para este cenário $(34.223,1$ t) é $0,6 \%$ maior do que no cenário original. As porcentagens de ocupação das moendas A, B e C passam a ser de $94,9 \%, 95,6 \%$ e $93,4 \%$, respectivamente.

\subsection{Cenário 3}

No sistema de transporte de cana na Usina São Martinho, $30 \%$ da cana transportada é inteira. As usinas que estão aprimorando seus sistemas de colheita e implantando a mecanização, como a referida usina, apresentam tendência à substituição da cana inteira pela picada. Na Usina São Martinho essa substituição tende a ocorrer de forma gradativa. O objetivo do cenário 3 é analisar os benefícios do aumento de 50\% (de 8 para 12) no número de rodotrens em substituição a um número proporcional de caminhões romeu e julieta. Este cenário também inclui um ponto específico de descarga instalado na moenda A para absorver o aumento de rodotrens. Note que a diferença em relação ao cenário anterior é a redução da frota de romeu e julieta (cana inteira), em vez da de treminhões (cana picada). Da mesma forma que no cenário anterior, este cenário considera uma nova distribuição dos pontos de descarga em relação ao cenário original, para que o desbalanceamento da carga de trabalho nas moendas seja reduzido e sua capacidade seja melhor aproveitada. Assim:

- A moenda A é alimentada pelos pontos $\mathrm{A}_{3}$ (novo ponto específico para descarga de rodotrens), $\mathrm{A}_{2}$ (ponto de descarga de veículos com cana picada se ocorrer falta de rodotrens descarregando no ponto $\mathrm{A}_{3}$ ) e $\mathrm{A}_{1}$ (que descarrega cana inteira).

- A moenda B é alimentada com a cana inteira que chega na usina por intermédio dos pontos $\mathrm{B}_{5}$ (onde descarregam caminhões com cana picada), $B_{6}$ e $B_{7}$ (que permanecem alimentando a moenda com cana inteira como no cenário original).

- A moenda C é alimentada com os mesmos pontos do cenário original, ou seja, pontos $\mathrm{C}_{10}, \mathrm{C}_{11}$ e $\mathrm{C}_{12}$.
Similarmente ao cenário anterior, a redução do número de caminhões romeu e julieta é realizada proporcionalmente ao aumento no número de rodotrens. Utilizando-se o procedimento anterior, 19 caminhões romeu e julieta devem sair do sistema. A Tabela 9 mostra que ocorre aumento de 18,5\% no tempo médio de espera dos caminhões rodotrens em razão do aumento no número desses veículos e da perda de prioridade em relação às unidades tratoras. Apesar de o número de treminhões permanecer o mesmo, o tempo médio de espera das unidades tratoras reduz-se em $8 \%$, pois o rodotrem não tem mais prioridade sobre unidades tratoras, mas estes têm prioridade sobre conjuntos julieta. Também pode ser observado na Tabela 9 que o aumento da descarga de cana picada resulta em maior tempo médio de espera para os conjuntos julieta $(34,9 \%)$, pois outros veículos, como a unidade tratora e o rodotrem, permanecem com prioridade em relação a este veículo.

Como era esperado, os tempos médios de espera para romeu e julieta com cana inteira e toco se reduzem em $15,7 \%$ e $25,8 \%$, respectivamente (lembre-se de que há redução do número dos primeiros veículos neste cenário).

Outro fator responsável por esse resultado é que a distribuição dos pontos de descarga entre as moendas faz com que a moenda $\mathrm{B}$ processe a maior parte da cana inteira e não receba caminhões rodotrens. Dessa forma, a influência do aumento desses veículos é menor para os veículos processados nessa moenda.

Em relação à taxa média de chegada dos veículos, há redução de $90,5 \%$ na taxa de treminhões inteiros e aumento de $60,8 \%$ na taxa de conjuntos julieta e unidades tratoras. Esses resultados podem ser explicados pelo fato de que, com o aumento da cana picada no pátio da usina, os desengates ocorrem com menor freqüência, enquanto a chegada de treminhões tende a aumentar, pois não há redução no número total desses veículos na usina e o tempo de espera de unidades tratoras é reduzido. A taxa média de chegada de rodotrens aumenta em $62,7 \%$, enquanto as taxas de caminhões romeu e julieta e toco sofrem reduções de $20 \%$ e $5 \%$, respectivamente, em função das alterações na composição da frota de veículos da usina. 
Tabela 9 - Resultados obtidos para o cenário 3 e comparados com os do cenário original.

\begin{tabular}{lcccccc}
\hline \multicolumn{1}{c}{ Tipo de caminhão } & $\begin{array}{c}\text { Tempo } \\
\text { médio } \\
\text { sistema (min) }\end{array}$ & $\begin{array}{c}\text { Desvio } \\
(\%)\end{array}$ & $\begin{array}{c}\text { Taxa de } \\
\text { cheg. } \\
\text { veic./min }\end{array}$ & $\begin{array}{c}\text { Desvio } \\
(\%)\end{array}$ & $\begin{array}{c}\text { Quant. cana } \\
\text { p/viagem (t) }\end{array}$ & $\begin{array}{c}\text { Quant. } \\
\text { média } \\
\text { espera (t) }\end{array}$ \\
\hline Rodotrem & 15,4 & $18,5 \%$ & 0,096 & $62,7 \%$ & 65 & 96,1 \\
Treminhão inteiro & 18,3 & $-8,0 \%$ & 0,009 & $-90,5 \%$ & 45 & 7,4 \\
Unidade tratora & 14,7 & $-20,9 \%$ & 0,238 & $60,8 \%$ & 15 & 52,5 \\
Conjunto julieta & 39,0 & $34,9 \%$ & 0,238 & $60,8 \%$ & 30 & 278,4 \\
Romeu e julieta (c. int.) & 19,3 & $-15,7 \%$ & 0,208 & $-19,4 \%$ & 25 & 100,4 \\
Romeu e julieta (c. pic.) & 20,3 & $-12,1 \%$ & 0,069 & $-19,8 \%$ & 25 & 35,0 \\
Toco & 16,4 & $-25,8 \%$ & 0,020 & $5,2 \%$ & 15 & 4,9 \\
Total & & & & & & 574,7 \\
\hline
\end{tabular}

\section{Quantidade média de} cana $(t /$ dia)

$34.428,9$

A Tabela 9 também mostra que a quantidade média de cana em espera no pátio da usina é de $574,7 \mathrm{t}$, o que representa um aumento de $13,1 \% \mathrm{em}$ relação ao cenário original. Esse resultado se deve, em grande parte, ao aumento da taxa de chegada de alguns veículos (rodotrens e treminhões) e pelo fato que, como no cenário anterior, o aumento do número de veículos gera aumento no tempo de espera no pátio, pois há limitações na capacidade de moagem. A quantidade média de cana descarregada por dia também aumenta em 1,2\% em relação ao cenário original, e as porcentagens de ocupação das moendas A, B e C passam a ser $94,5 \%, 95,9 \%$ e $97 \%$, respectivamente. Esses resultados mostram que, com o aumento da cana picada no sistema, a moenda $\mathrm{C}$, que processa apenas cana picada, apresenta maior taxa de ocupação do que no cenário anterior.

\subsection{Resumo das medidas de desempenho obtidas nos cenários 1,2 e 3}

A Tabela 10 apresenta um resumo das medidas de desempenho dos cenários original e 1,2 e 3 .

Tabela 10 - Comparação entre as medidas de desempenho dos cenários 1-3.

\begin{tabular}{lcccc}
\hline Cenário & $\begin{array}{c}\text { Quantidade } \\
\text { média espera } \\
Q=\sum_{i} Q_{i}(\mathbf{t})\end{array}$ & $\begin{array}{c}\text { Variação } \\
\mathbf{p} / \text { original }\end{array}$ & $\begin{array}{c}\text { Quantidade } \\
\text { total p/ dia } \boldsymbol{Q}_{t}(\mathbf{t})\end{array}$ & $\begin{array}{c}\text { Variação } \\
\mathbf{p} / \text { original }\end{array}$ \\
\hline Original & 508,2 & & $34.009,7$ & \\
Cenário 1 & 439,4 & $-13,5 \%$ & $34.392,4$ & $1,1 \%$ \\
Cenário 2 & 599,3 & $17,9 \%$ & $34.223,1$ & $0,6 \%$ \\
Cenário 3 & 574,7 & $13,1 \%$ & $34.428,9$ & $1,2 \%$ \\
\hline
\end{tabular}


Pode-se concluir que:

1. O cenário 1 apresenta melhorias significativas para o sistema, ou seja, há redução de 13,5\% na quantidade média de cana em espera e aumento porcentual (mesmo que pequeno, ou seja, de $1,1 \%$ ) na quantidade de cana moída.

2. O cenário 2 mostra que, apesar das mudanças proporcionais no número de rodotrens e treminhões, ocorre maior congestionamento de veículos no pátio em relação ao cenário original $(17,9 \%)$. Isso porque rodotrens (cujo número foi aumentado) e unidades tratoras (reduzido) têm prioridade no sistema em relação a outros veículos e concorrem pela mesma moenda, mesmo estando em filas de pontos diferentes da mesma moenda. A quantidade média de cana descarregada aumenta em 0,6\% (Tabela 10) em relação ao cenário original.

3. O cenário 3 mostra que, apesar das mudanças proporcionais no número de rodotrens e romeu e julieta, ocorre maior congestionamento de veículos no pátio, em relação ao cenário original $(13,1 \%)$. No entanto, o cenário 3 apresenta resultados um pouco melhores do que os obtidos no cenário 2. A quantidade média de cana descarregada aumenta 1,2\% (Tabela 10) em relação ao cenário original. A interpretação desses resultados é similar à do cenário 2 .

Portanto, pode-se concluir que, do ponto de vista das medidas escolhidas para análise, o cenário 1 apresenta melhor desempenho e pode ser considerado para substituir o cenário original.

Os cenários 2 e 3, apesar de aumentarem um pouco a quantidade média de cana descarregada em relação ao cenário original, aumentam significativamente a quantidade média de cana em espera, assim, parecem menos promissores. Outros cenários poderiam ter sido analisados neste trabalho de maneira similar.

\section{Conclusões}

Este trabalho apresentou um estudo do sistema de recepção de cana da Usina São Martinho, compreendido da balança até as moendas. Por se tratar de um sistema complexo, com muitas variáveis aleatórias, regras operacionais e recursos envolvidos, optou-se pela utilização da técnica de simulação em vez de um modelo analítico de teoria de filas. Um modelo de simulação foi construído no software Arena e aplicado; os resultados obtidos mostraram que o modelo é capaz de representar satisfatoriamente o sistema.

Além da configuração atual do sistema, outros cenários foram investigados e seus desempenhos comparados com o do atual. Essa análise mostrou que o cenário 1 (todos os treminhões desengatam seus conjuntos julieta no estoque do pátio) apresenta o melhor desempenho do ponto de vista da quantidade média de cana em espera no pátio da usina $(Q)$ e da quantidade média de cana descarregada por dia nas moendas $\left(Q_{t}\right)$. Além disso, o cenário 1 envolve alterações relativamente simples de serem realizadas no sistema. Os cenários 2 (aumento de $50 \%$ do número de rodotrens e redução proporcional do número de treminhões) e 3 (aumento de $50 \%$ do número de rodotrens e redução proporcional do número de romeu e julieta), apesar de aumentarem um pouco $Q_{t}$ em relação ao cenário original, aumentam significativamente $Q$. Outros cenários poderiam ter sido considerados neste trabalho, e a análise seria similar.

Uma das contribuições deste estudo é mostrar a importância do sistema de recepção de cana na integração das operações agrícolas e industriais. Nesse sistema, a política de despacho de veículos e as operações no pátio da usina dependem da capacidade e da operação das moendas. Portanto, o estudo de mudanças na política de despacho ou na composição da frota de veículos deve considerar o balanceamento e a capacidade das moendas.

O sistema de transporte agrícola de uma usina de açúcar envolve outros tópicos importantes para pesquisa, entre eles: o despacho de veículos ao campo, a gestão das operações de colheita e transbordo nas frentes de corte de cana e o problema de filas de espera de máquinas e caminhões no campo. Em particular, uma perspectiva interessante para pesquisa futura é a aplicação do presente modelo de simulação para analisar sistemas de recepção de cana em outras usinas com características similares às da Usina São Martinho. 


\section{Agradecimentos}

Agradecemos aos Profs. João Alexandre Widmer, Miguel Cezar Santoro e Flávio C. F. Fernandes e aos três revisores anônimos pelos úteis comentários e sugestões. Também agradecemos à Usina São Martinho pela valiosa colaboração durante a realização do estudo de caso. Esta pesquisa contou com apoio da Fapesp (processo 98/03314-4).

\section{Referências Bibliográficas}

BANKS, J. Handbook of Simulation. Atlanta: John Wiley \& Sons, 1998.

CAIXETA FILHO, J. V.; SILVA, N. D. V.; GAMEIRO, A. H.; LOPES, R. L.; GALVANI, P. R. C.; MARTIGNON, L. M.; MARQUES, R. W. C. Competitividade no agribusiness brasileiro: a questão do transporte em um contexto logístico. In: FARINA, E. M. E. Q.; ZYLBERSZTAJN, D. (Coord.). Competitividade no agribusiness brasileiro. São Paulo: PENSA/FIA/FEA/USP, 1998. Programa de Estudos dos Negócios do Sistema Agroindustrial (PENSA)/Fundação Instituto de Administração (FIA)/Faculdade de Economia, Administração e Contabilidade (FEA). 194p. Disponível em URL:<http://www.fea.usp.br/fia/pensa/pdf/ logistica.pdf <http://www.fea.usp.br/fia/pensa/pdf/ acucar.pdf>. Acesso em: 10 dez. 1999.

COSTA, M. A. Pesquisa operacional aplicada à agroindústria. In: BATALHA, M. O. (Coord.). Gestão agroindustrial. Atlas, São Paulo: Grupo de Estudos Agroindustriais (GEPAI), 1997. v. 2, cap. 1, p. 15-64.

EID, F. Progresso técnico na agroindústria sucroalcooleira. Revista Informações Econômicas, v. 26, n. 5, p. 29-36, mai. 1996.

HAHN, M. H. SISTEC: Simulador de sistema de transporte da cana-de-açúcar. 1994. Dissertação (Mestrado em Eng. Elétrica) - Faculdade de Engenharia Elétrica e Computação, Universidade Estadual de Campinas, Campinas.

IANNONI, A. P. Análise do sistema logístico de descarga de cana-de-açúcar: um estudo de caso em uma grande usina na região de Ribeirão Preto. 2000. Dissertação (Mestrado em Eng. Produção) Departamento de Eng. de Produção, Universidade Federal de São Carlos, São Carlos, 2000.

KELTON, W. D.; SADOWSKI, R. P.; SADOWSKI, D. A Simulation with Arena. New York: McGraw-Hill, 1998.

LAW, A. M.; KELTON, W. D. Simulation modeling and analysis. 2. ed. New York: McGraw-Hill, 1991.
LOPES M. B. Simulação de um sistema de carregamento e transporte de cana-de-açúcar. 1995. Dissertação (Mestrado em Eng. Agrícola) Escola Superior de Agricultura "Luiz de Queiroz", Universidade de São Paulo, Piracicaba.

MATHEW, J.; RAJENDRAN, C. Scheduling of maintenance activities in a sugar industry using simulation. Computers in industry, n. 21, p. 331-334, 1993.

PC, PALISADE CORPORATION. Best fit for Windows: Help. 2. ed. New York, 1996.

PEGDEN, C. D., SHANNON, R. E.; SADOWSKI, R. P. Introduction to simulation using SIMAN. 2. ed. New York: McGraw-Hill, 1995.

SHANNON, R. E. Systems simulation: the art and science. New Jersey: Prentice-Hall, Inc. Englewood Cliffs, 1975.

SMC, SYSTEMS MODELING CORPORATION. ARENA user's guide. Sewickey, 1994, $4 \mathrm{v}$.

WAACK, R. S.; NEVES, M. F.; MORAES, S.; MARINO, M. K.; MAMONE, A.; SZASZ, A. H. Sistema agroindustrial da cana-de-açúcar/Sistema agroindustrial da soja". In: FARINA, E. M. E. Q.; ZYLBERSZTAJN, D. (Coord.). Competitividade no agribusiness brasileiro. São Paulo: PENSA/FIA/ FEA/USP, 1998. Programa de Estudos dos Negócios do Sistema Agroindustrial (PENSA)/Fundação Instituto de Administração (FIA)/Faculdade de Economia, Administração e Contabilidade (FEA). 194p. Disponível em: URL <http://www.fea.usp.br/ fia/pensa/pdf/acucar.pdf>. Acesso em: 10 dez. 1999.

YAMADA, M. C. Modelagem das cadeias de atividades produtivas da indústria sucroalcooleira visando à aplicação em estudos de simulação. 1999. Dissertação (Mestrado em Eng. Mecânica) Escola de Engenharia de São Carlos, Universidade de São Paulo, São Carlos.

YOSHIZAKI, H. T. Y. Análise de desempenho operacional de sistemas logísticos e de transportes: aplicações de redes de filas. 1989. Dissertação (Mestrado em Eng. Produção) - Escola Politécnica, Universidade de São Paulo, São Paulo. 


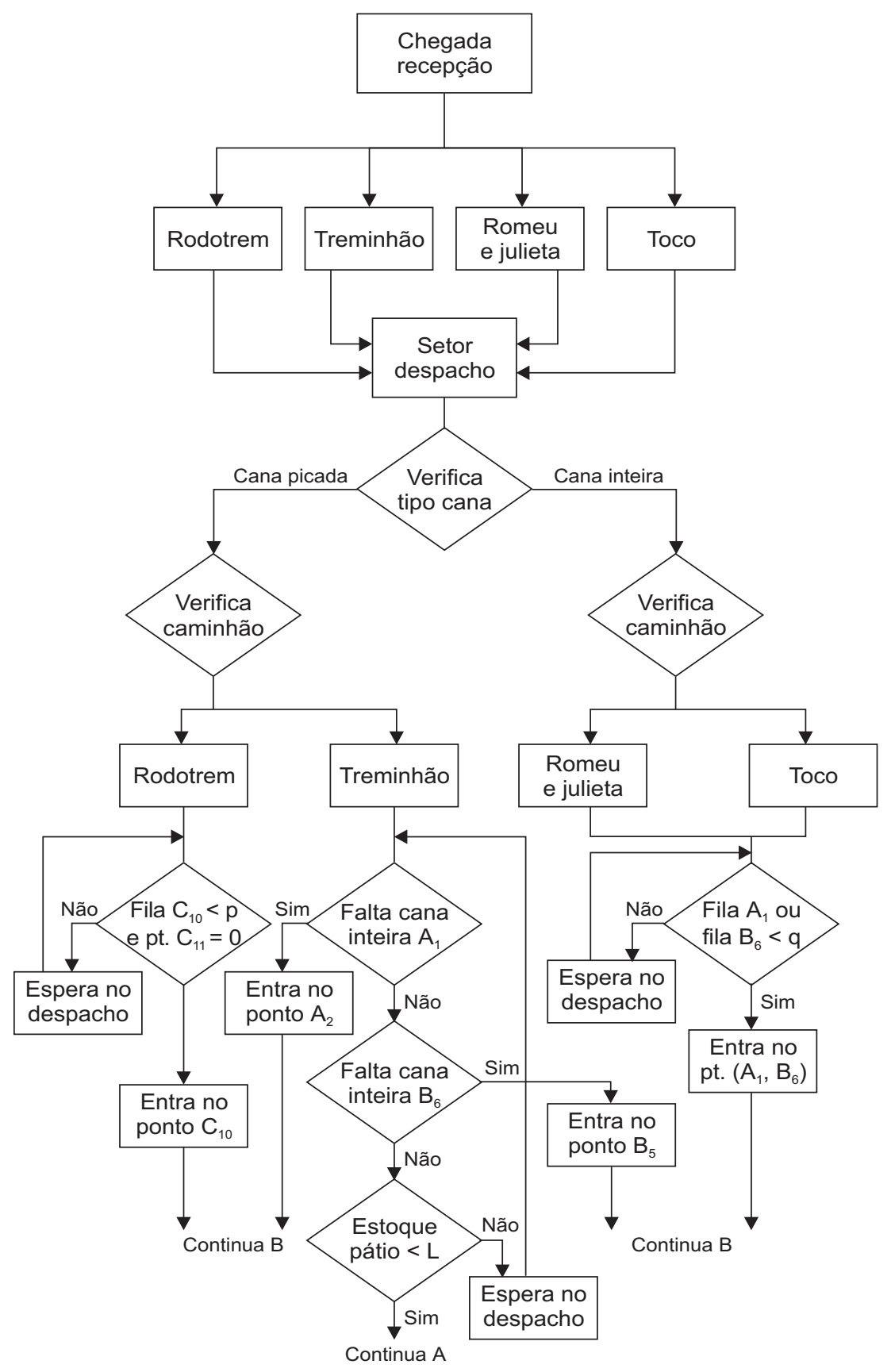

Anexo: Fluxograma do modelo de simulação. 


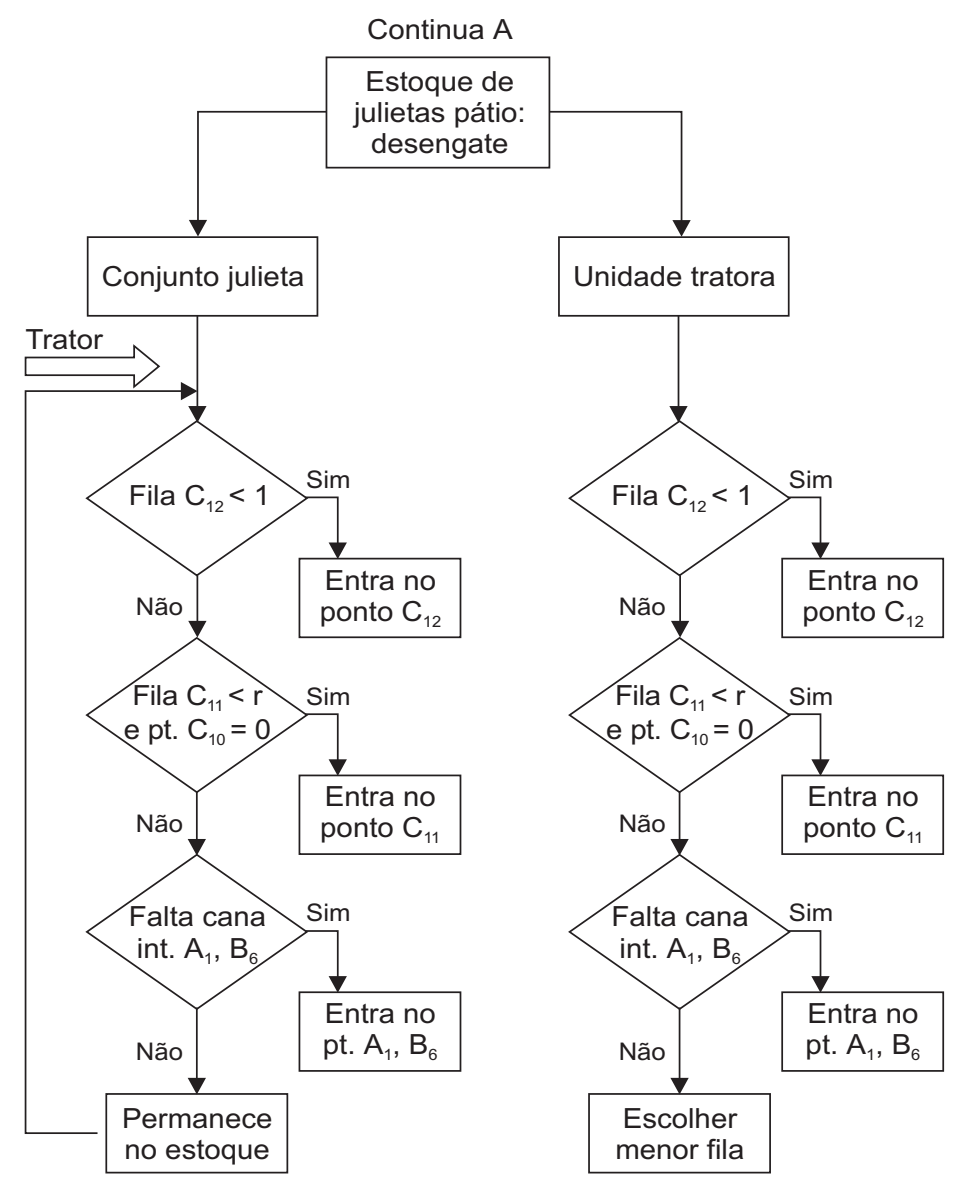

Continua B

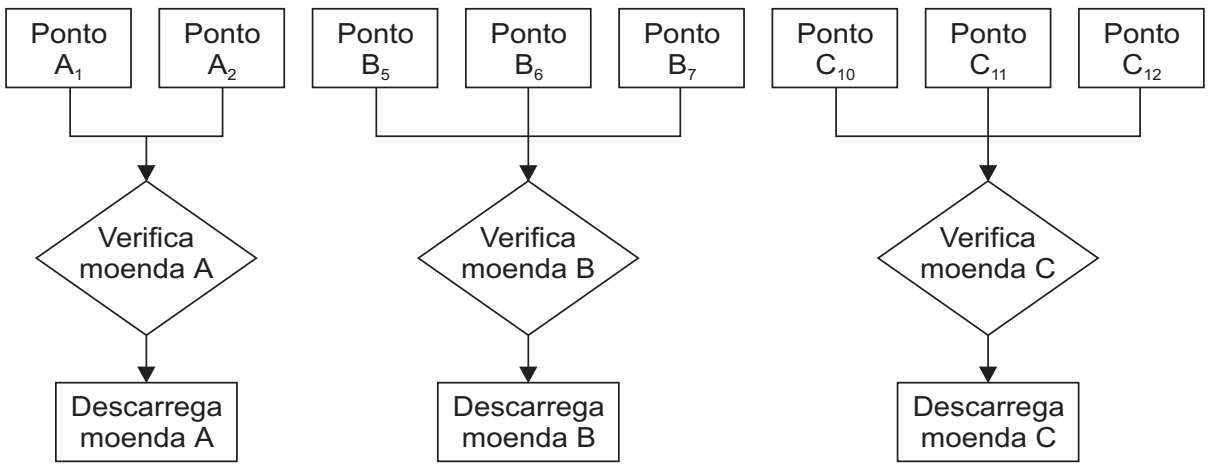

Anexo: Fluxograma do modelo de simulação (continuação). 


\section{ANALYSIS OF THE LOGISTICS SUPPLY SYSTEM OF SUGAR CANE: A CASE STUDY USING DISCRETE SIMULATION}

\section{Abstract}

Logistic systems are fundamental to improve the operational efficiency of sugar cane plants integrating agricultural and industrial operations. This article presents a case study in the logistic supply system of one the largest Brazilian sugar case plants, the Usina São Martinho, located near Ribeirão Preto, SP. The aim of the study is to analyze the performance of the system in front of the mills, and to investigate alternative configurations and policies for system operation. Due to several uncertainty sources and the operational complexity of the system, the method is based on discrete simulation techniques. The mais performance measures are related to time averages spent in the supply system, and mean unloading rates in the mills.

Key words: sugar, sugar cane suplly system, simulation, logistics, agro-industry. 